\title{
Preparação e Caracterização de Microfibras de Poli(Álcool Vinílico)/Dióxido de Titânio
}

\author{
Ariadne H. P. de Oliveira, José Américo S. Moura, Helinando P. de Oliveira \\ Instituto de Pesquisa em Ciência dos Materiais, UNIVASF
}

\begin{abstract}
Resumo: Compósitos de poli(álcool vinílico)/dióxido de titânio preparados pela técnica de eletrofiação são potenciais candidatos para aplicações nas quais grande absorbância na região do ultra-violeta e transparência na região do visível são requeridas. A incorporação de semicondutor nas fibras pode ser inferida pela redução da impedância elétrica das fibras fabricadas por eletrofiação, como consequência do aumento na densidade de grãos de semicondutor dispersos nas fibras poliméricas. As propriedades térmicas do compósito polímero/semicondutor são dominadas pela resposta do PVA sendo a influência do dióxido de titânio detectada no espectro de absorção de luz pela maximização da absorbância na faixa de $240 \mathrm{~nm}$ a $400 \mathrm{~nm}$. Os resultados indicam que o compósito de $\mathrm{PVA} / \mathrm{TiO}$, pode ser convenientemente aplicado como curativo com proteção adicional contra efeitos de radiação ultravioleta (UVA e UVB) na pele humana. Uma aplicação adicional para o compósito $\mathrm{PVA} / \mathrm{TiO}_{2}$ foi abordada com o estudo dos processos fotocatalíticos na degradação da rodamina $\mathrm{B}$.
\end{abstract}

Palavras-chave: Eletrofiação, compósitos poliméricos, dióxido de titânio, poli(álcool vinílico).

\section{Preparation and Characterization of Polyvinyl Alcohol/Titanium Dioxide Microfibers}

\begin{abstract}
Electrospun composites of polyvinyl alcohol/titanium dioxide are potential candidates for applications that require high level of absorbance in the UV and transparency in the visible region. The incorporation of semiconductor particles in the core of fibers can be inferred from the reduction in the electrical impedance of electrospun fibers, as a consequence of the increased density of semiconductor granules along the fiber. The thermal properties of PVA dominate in the complete response of the composite while the influence from titanium dioxide is noted with an increased absorption from $240 \mathrm{~nm}$ to $400 \mathrm{~nm}$. The results indicate that the PVA/TiO, composites can be applied as wound dressing with additional protection against effects of ultraviolet radiation (UVA and UVB) on human skin. An additional application studied here was based on the use of $\mathrm{PVA} / \mathrm{TiO}_{2}$ nanocomposites as active agent in photodegrading rhodamine $\mathrm{B}$.
\end{abstract}

Keywords: Electrospinning, polymeric composites, titanium dioxide, polyvinyl alcohol.

\section{Introdução}

A eletrofiação representa um método simples e de baixo custo que promove a fabricação de uma grande quantidade de fibras ultrafinas. Baseadas nesta propriedade, diversas aplicações têm sido consideradas para esses materiais, das quais podemos destacar: novos biomateriais, detectores de voláteis ${ }^{[1]} \mathrm{e}$ dispositivos "labs on a chip"[2]. A potencialização de aplicações médicas como medicina regenerativa ${ }^{[3]} /$ substituição de pele ${ }^{[4]}$ e liberação controlada de fármacos ${ }^{[5]}$ depende da aplicação de hidrogéis (naturais e sintéticos) com potencial biocompatibilidade e pequeno tamanho de poro associado à elevada área superficial. Em todos os casos descritos anteriormente, o uso de hidrogéis como a quitosana e o PVA são fundamentais para a produção de micro/nano fibras ${ }^{[6]}$. No caso do PVA, (polímero hidrofílico e semicristalino) é observado que a elevada biocompatibilidade e biodegradabilidade representam importantes vantagens para aplicações médicas.

Adicionalmente a essas propriedades, a síntese de nanofibras de PVA na presença de outros componentes promove a elevação nas propriedades físico-químicas do material sintetizado, considerado como excelente protótipo para aplicações em biomedicina e liberação controlada de fármacos ${ }^{[7]}$.

Nesta direção, tem sido progressivamente descrito na literatura a preparação de nanofibras de PVA e quitosana ${ }^{[6]}$, nanotubos de carbono multiparedes/quitosana ${ }^{[8]}$, gelatina ${ }^{[4]}$, poliuretano ${ }^{[9]}$, celulose $^{[10]}$ e fibras naturais ${ }^{[1]}$ (aplicadas na área de materiais verdes) poli(acetato de vinila) ${ }^{[5]}$ e poli(hidróxi buritato) ${ }^{[12]}$.
Também tem sido explorada a incorporação de outros elementos como o $\mathrm{Cu}(\mathrm{II})^{[13]}$ nas fibras de PVA com o intuito de promover a imobilização catalítica.

A incorporação de nanopartículas de semicondutores (como o $\mathrm{TiO}_{2}$ ) nas nanofibras poliméricas introduz as vantagens de elevada área superficial com as propriedades intrínsecas do semicondutor além do fato de que o compósito $\mathrm{PVA} / \mathrm{TiO}$, promove a minimização dos processos agregacionais do semicondutor ${ }^{[14]}$.

Neste sentido, diversos trabalhos têm sido desenvolvidos com a microencapsulação do PVA, o que caracteriza um importante processo na aplicação do compósito como dispositivo eletroforético ${ }^{[14]}$. Em especial, os grupos hidroxila promovem inibição no processo de agregação do $\mathrm{TiO}_{2}$, produzindo boa dispersão de partículas na fibra ${ }^{[15]}$.

Quando aplicado como fotocatalisador, em processos oxidativos avançados (POA), a imobilização representa um importante passo para posterior separação do fotocatalisador do meio aquoso. Com esse fim, sistemas porosos de níquel/PVA têm sido descritos na literatura ${ }^{[16]}$.

Em adição às aplicações anteriores descritas ${ }^{[17]}$, um uso bastante comum para as nanopartículas de semicondutores (óxido de zinco/dióxido de titânio) é o de bloqueadores de radiação ultra-violeta, com potencial aplicação como cosméticos para proteção solar, dados os efeitos nocivos da radiação ultravioleta sobre a pele humana. É sabido que a radiação solar compreende a região de raios- $\mathrm{X}$ até ondas de rádio e que a radiação ultravioleta é classificada em três tipos: UVA, UVB e UVC. A radiação UVC

Autor para correspondência: Helinando Pequeno de Oliveira, Instituto de Pesquisa em Ciência dos Materiais,

Universidade Federal do Vale do São Francisco - UNIVASF, CEP 48902-300, Juazeiro, BA, Brasil, e-mail: helinando@gmail.com 
é praticamente absorvida pela camada de ozônio da estratosfera ${ }^{[18]}$ enquanto que a radiação restante é distribuída como 1-5\% de UVB e 95-99\% de UVA. A radiação UVB, apesar de percentualmente baixa, é potencialmente absorvida pelas camadas superiores da epiderme, promovendo riscos elevados associados ao envelhecimento e câncer de pele.

O dióxido de titânio tem sido correntemente aplicado como protetor solar físico atuando na proteção da pele contra radiação UVB $^{[19]}$ enquanto a radiação UVA é predominantemente absorvida pelo óxido de zinco ${ }^{[19]}$.

Por outro lado, a incidência direta de radiação UV sobre as nanopartículas de dióxido de titânio promove elétrons da banda de valência para a banda de condução do semicondutor com a geração de pares elétron-buraco e a subsequente recombinação/migração para a superfície das partículas (em tempos da ordem de $0.1 \mathrm{ps})^{20]}$. Em meio aquoso, os elétrons reagem com o oxigênio enquanto que os buracos reagem com os íons de hidroxila promovendo a formação de radicais $\bullet \mathrm{OH}$.

A literatura reporta que os radicais permanecem na superfície das nanopartículas e apresentam razoável penetração na pele humana ${ }^{[20]}$ com posterior degradação do DNA ${ }^{[21]}$.

Para evitar com que esse processo seja estabelecido, procedimentos de revestimento têm sido desenvolvidos como forma de minimizar a ação fotocatalítica do dióxido de titânio, com o uso de sílica e alumina na formulação de protetores solares ${ }^{[22]}$.

Por sua vez, a aplicação da técnica de eletrofiação permite a produção de nanofibras contínuas que possuem uma área superficial muito grande formando uma rede com várias interconexões que facilitam a troca gasosa, o que possibilita a regeneração da pele danificada ${ }^{[23,24]}$. Um procedimento bastante usado também tem sido a incorporação de agentes antimicrobianos ${ }^{[24]}$ com nanopartículas de prata e dióxido de titânio ${ }^{[25]}$, possibilitando com que além da proteção contra radiação UV ocorra ação antimicrobiana. Com isso, é possível estabelecer a deposição direta das nanofibras produzidas pela eletrofiação sobre a região de interesse, sendo necessário posicionar a pele do paciente na direção de ejeção das fibras do compósito, permitindo assim com que ocorra a deposição da nanofibra, formando uma estrutura porosa e com ação regenerativa sobre a região a ser protegida. Baseado nestas propriedades é possível visualizar que a conjunção das propriedades do PVA (nanofios) e de nanopartículas de $\mathrm{TiO}_{2}$ possibilita uma variedade de aplicações. Para tanto, torna-se iminente a necessidade de identificar a concentração ótima do dióxido de titânio distribuído nas fibras de PVA como forma de minimizar a agregação do semicondutor e potencializar o uso como dispositivo. Neste sentido, a interação entre os componentes das fibras foi analisada a partir da medida das propriedades elétricas, térmicas e estruturais do material sintetizado. A absorbância de luz foi usada tanto na medida da eficiência da fibra como bloqueador de radiação solar (em especial na região do ultravioleta) quanto na quantificação do processo de catálise induzido pelas nanofibras imersas em solução aquosa de rodamina $\mathrm{B}$.

\section{Experimental}

\section{Materiais}

Dióxido de titânio (anatase) e poli(álcool vinílico) (com grau de hidrólise de $99 \%$ ) e pureza superior a $99 \%$ foram adquiridos junto à Aldrich (EUA) enquanto que a rodamina $\mathrm{B}$ foi adquirida junto à Vetec (Brasil). O tamanho médio das partículas de $\mathrm{TiO}_{2}$ é de $25 \mathrm{~nm}$ com pureza de $99,7 \%$ e área superficial específica de $200 \mathrm{~m}^{2} \cdot \mathrm{g}^{-1}$.

\section{Métodos analíticos}

A técnica de eletrofiação é baseada na aplicação de uma alta tensão entre a ponta de prova de uma agulha e um alvo aterrado. A agulha é conectada a um compartimento que contém solução polimérica a fluxo contínuo de hidrogel da ordem de $166 \mu \mathrm{L} / \mathrm{min}$ (ausência de campo e à pressão constante). A gotícula de solução na extremidade da ponta da agulha é submetida a um potencial da ordem de $15 \mathrm{kV}$ a partir do qual ocorre a formação de nanofibras em direção ao alvo aterrado. A caracterização dos filmes foi realizada a $25^{\circ} \mathrm{C}$ a partir de uma analisador de impedância Solartron 1260 conectado a uma interface dielétrica (Solartron 1296) na faixa de frequência de $1 \mathrm{~Hz}$ a $1 \mathrm{MHz}$ (usando 10 pontos por década) com uma excitação AC de $1 \mathrm{~V}$ e nenhuma polarização externa.

As imagens foram obtidas a partir de um microscópio eletrônico de varredura (MEV) Hitachi TM 1000 enquanto que os termogramas foram medidos a partir de um DSC Shimadzu DSC60 com taxa de aquecimento de $10{ }^{\circ} \mathrm{C} / \mathrm{min}$ e temperatura entre $30{ }^{\circ} \mathrm{C}$ e $250{ }^{\circ} \mathrm{C}$. As medidas foram realizadas sob fluxo constante de $50 \mathrm{~mL} / \mathrm{min}$ de $\mathrm{N}_{2}$ enquanto que a massa das amostras utilizada no experimento foi de $1,5 \mathrm{mg}$.

A estrutura dos componentes do material foi analisado com o uso de um FTIR Shimadzu modelo IR-Prestige 21 sendo preparadas pastilhas de $\mathrm{KBr}$ contendo $0.1 \mathrm{mg}$ das nanofibras de interesse enquanto que as medidas de absorbância foram realizadas com o uso de um espectrofotômetro FEMTO modelo 800XI.

Os ensaios de fotodegradação foram realizados a partir da iluminação do reator (béquer com a solução de rodamina $\mathrm{B}$ a uma concentração de $10^{-5} \mathrm{M}$ com fibras de $\mathrm{TiO}_{2} / \mathrm{PVA}$ ) com uma lâmpada halógena de $60 \mathrm{~W}$ disposta a $30 \mathrm{~cm}$ da amostra, como forma de minimizar o efeito do aquecimento da solução sobre o processo de fotodegradação do corante.

\section{Procedimento experimental}

A dispersão das nanopartículas de dióxido de titânio (com concentração variando de $0,25 \mathrm{mg} \cdot \mathrm{mL}^{-1}$ a $2,5 \mathrm{mg} \cdot \mathrm{mL}^{-1}$ ) em água foi obtida após sonicação por 5 minutos. Seguido a essa etapa, o poli(álcool vinílico) (a uma concentração de $80 \mathrm{mg} \cdot \mathrm{mL}^{-1}$ ) foi introduzido em solução, e após três horas sob aquecimento $\left(70^{\circ} \mathrm{C}\right)$ foi verificada a completa solubilização do polímero e nanopartículas de dióxido de titânio.

A uma diferença de potencial da ordem de $15 \mathrm{kV}$ e distância entre a extremidade da agulha e o alvo de aproximadamente $8 \mathrm{~cm}$ foram introduzidos dois eletrodos paralelos (agulhas metálicas mantidas a uma distância fixa de $10 \mathrm{~mm}$ uma da outra) atuando como um porta amostras a partir do qual a resposta elétrica foi analisada.

O conjunto foi aterrado e posicionado sobre o alvo, de tal forma que as fibras preferencialmente tendiam a se depositar perpendicularmente às agulhas, preenchendo um espaço de $10 \mathrm{~mm}$ entre as mesmas. As amostras preparadas neste trabalho tiveram espessura na faixa entre $100 \mu \mathrm{m}$ e $110 \mu \mathrm{m}$. O esquema da montagem é mostrado na Figura 1.

Com o aumento no tempo de deposição, as fibras são progressivamente depositadas entre as agulhas e o espaço entre elas ( 10 mm) é completamente preenchido com uma rede de fios, estabelecendo contato elétrico entre os eletrodos e promovendo a circulação de corrente a partir de excitação com um campo elétrico externo. O processo de deposição tem duração total de 11 minutos, o que é acompanhado do crescimento de um filme de aproximadamente $100 \mu \mathrm{m}$ de espessura entre os eletrodos metálicos a partir do qual 


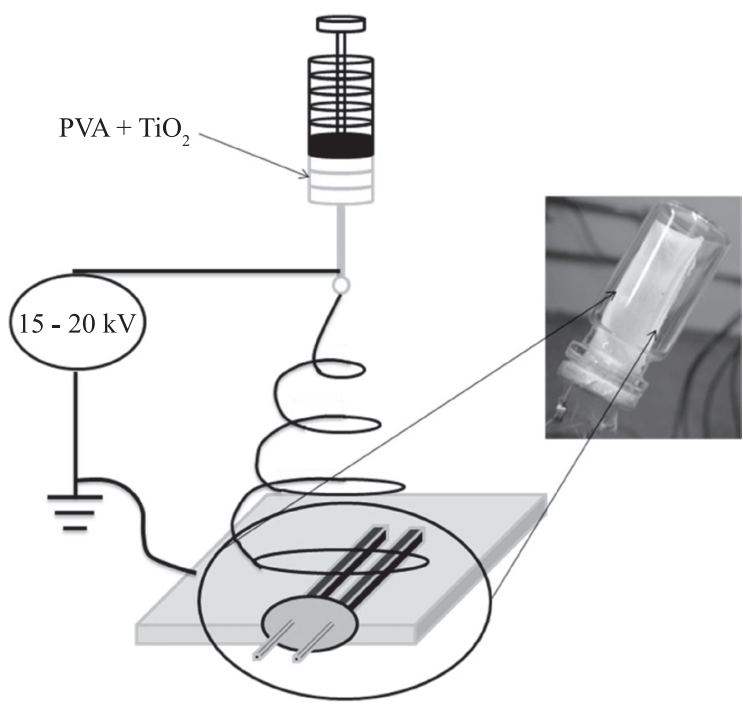

Figura 1. Esquema de deposição de fibras sobre a superfície de eletrodos paralelos a partir da técnica de eletrofiação.

se têm caracterizadas as propriedades físico-químicas do material depositado.

\section{Resultados e Discussão}

A distribuição das fibras de PVA depositadas entre os eletrodos metálicos pode ser visualizada diretamente a partir de MEV, como indicado na Figura 2. A introdução das nanopartículas de dióxido de titânio no PVA promove a produção de fibras mistas, a partir das quais é verificada a presença de grânulos do semicondutor como visualizado claramente pelos pontos brilhantes na microscopia da Figura 3. O aspecto visual do filme depositado sobre o porta-amostras é mostrado na fotografia inserida no canto esquerdo da Figura 3.

Relativamente à resposta térmica do sistema, o poli(álcool vinílico) é caracterizado por duas temperaturas críticas ${ }^{[26]}$ (temperatura de transição vítrea a $82{ }^{\circ} \mathrm{C}$ e temperatura de fusão de $230{ }^{\circ} \mathrm{C}$ ). Os termogramas das fibras sintetizadas (como mostra a Figura 4) indicam temperatura de transição vítrea de $75,1{ }^{\circ} \mathrm{C}$ e temperatura de fusão de $223,7^{\circ} \mathrm{C}$. Com a inclusão das nanopartículas de dióxido de titânio ocorre uma redução significativa na entalpia de fusão (que passa de $-84,67 \mathrm{~J} . \mathrm{g}^{-1}$ para $-26,11 \mathrm{~J} . \mathrm{g}^{-1}$ ) caracterizando uma diminuição na cristalinidade da matriz de PVA.

Por sua vez, a impedância elétrica do filme formado pelas nanofibras é medida na direção longitudinal com a aplicação de potencial elétrico entre os eletrodos metálicos usados como suporte durante o processo de deposição. Com a progressiva inserção de dióxido de titânio durante a produção dos nanofios passa a surgir a possibilidade de formação de caminhos de percolação para a circulação de corrente, em especial nos pontos de intersecção entre fibras adjacentes.

Como podemos verificar na Figura 5, a resposta elétrica do eletrodo aberto (antes da deposição das fibras) é caracterizado por um valor de impedância (Z'), no regime de baixas frequências, extremamente elevado (da ordem de $10^{10} \Omega$ ) caracterizando a resposta elétrica do ar. A deposição das fibras de PVA com quantidade crescente de $\mathrm{TiO}_{2}$ também afeta diretamente a impedância da amostra com a progressiva redução de Z', como mostra a Figura 5.

Note que o aumento na concentração de nanopartículas de dióxido de titânio torna a impedância em baixas frequiências progressivamente menor, ao mesmo tempo em que a região de cargas livres (invariância de Z' com a mudança da frequência) ${ }^{[27,28]}$

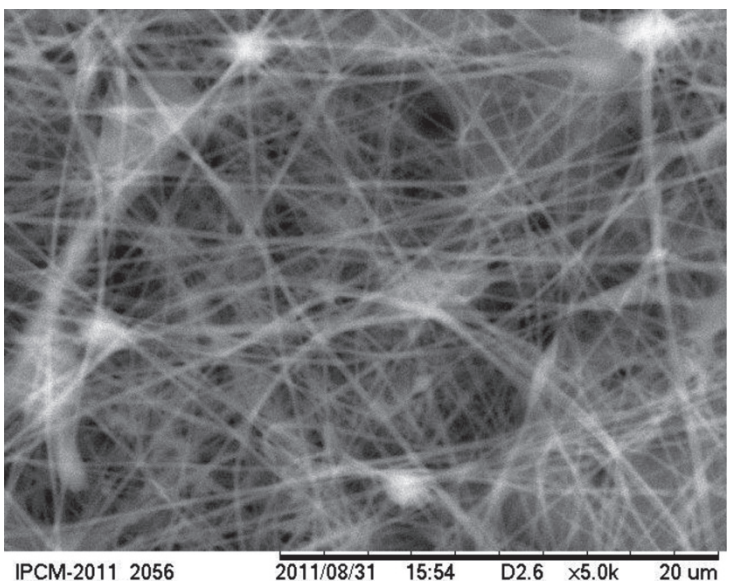

Figura 2. MEV de fibras de PVA ( $\left.80 \mathrm{mg} \cdot \mathrm{mL}^{-1}\right)$ depositadas pela técnica de eletrofiação.

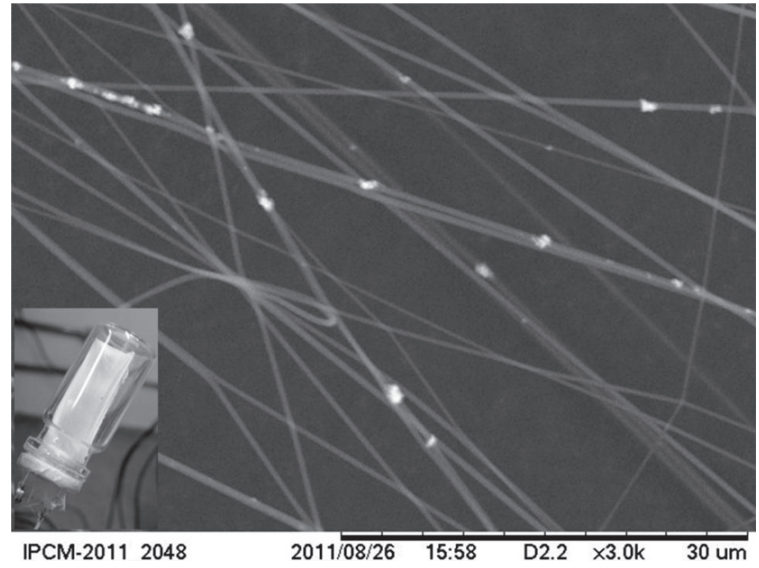

Figura 3. MEV de compósito de PVA $\left(80 \mathrm{mg} \cdot \mathrm{mL}^{-1}\right) / \mathrm{TiO}_{2}\left(2,5 \mathrm{mg} \cdot \mathrm{mL}^{-1}\right)$ depositado pela técnica de eletrofiação. No canto esquerdo é apresentada a imagem das fibras depositadas sobre o porta-amostras.

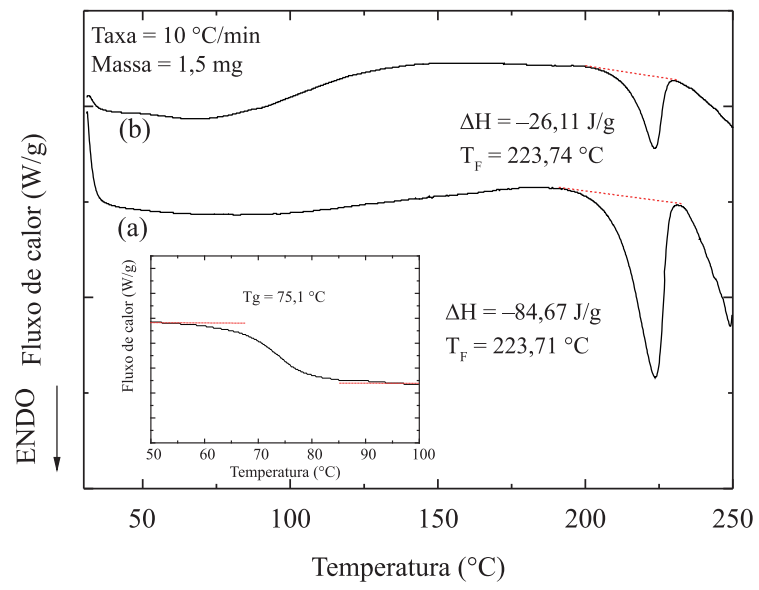

Figura 4. Curvas de DSC das fibras puras de PVA $\left(80 \mathrm{mg}^{\mathrm{mL}} \mathrm{L}^{-1}\right)$ (curva a) e compósito de PVA ( $\left.80 \mathrm{mg} \cdot \mathrm{mL}^{-1}\right) / \mathrm{TiO}_{2}\left(2,5 \mathrm{mg} \cdot \mathrm{mL}^{-1}\right)$ (curva b). Na curva inserida no canto esquerdo é apresentada em detalhe a região a partir da qual se tem calculada a temperatura de transição vítrea.

passa a ser mais pronunciada nas amostras com maior quantidade de semicondutor.

Esse processo atinge a saturação a uma concentração de $1 \mathrm{mg} \cdot \mathrm{mL}^{-1}$ de nanopartículas de $\mathrm{TiO}_{2}$ (fornecendo impedância da ordem de $10 \mathrm{M} \Omega$ ) a partir do que se dá a agregação dos grãos de 


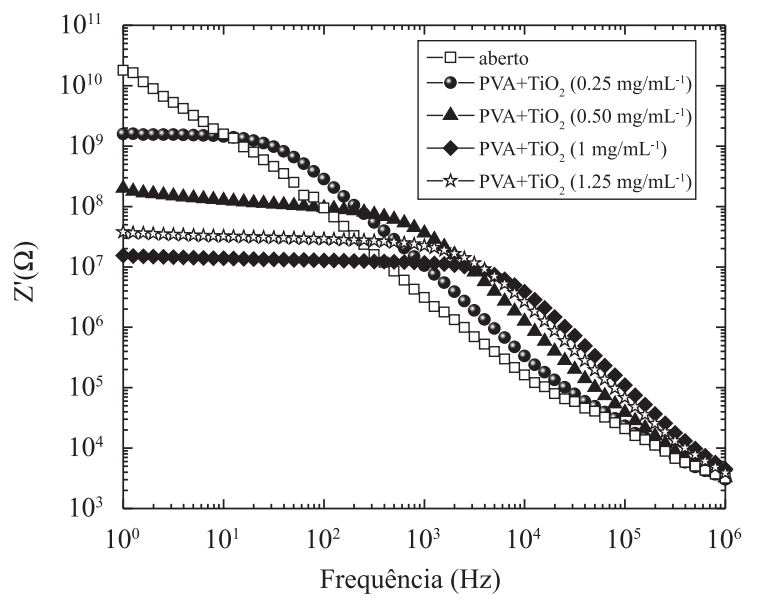

Figura 5. Espectro da parte real da impedância de compósitos de PVA ( $\left.80 \mathrm{mg} \cdot \mathrm{mL}^{-1}\right) / \mathrm{TiO}_{2}$ como função da concentração de $\mathrm{TiO}_{2}$ (concentração variando de $0,25 \mathrm{mg} \cdot \mathrm{mL}^{-1}$ a $1,25 \mathrm{mg} \cdot \mathrm{mL}^{-1}$ ).

TiO induzindo consequente elevação no nível de impedância das fibras, o que coincide com o processo de deposição de agregados de $\mathrm{TiO}_{2}$ separados das microfibras de PVA (visualizado diretamente nas imagens de MEV), o que afeta consequentemente os mecanismos de percolação da corrente elétrica.

A estrutura das fibras preparadas por eletrofiação foram analisados também a partir dos espectros de FTIR. Como mostra a Figura 6, a assinatura do PVA (curva (a)) é caracterizada pelas bandas 3200-3570 $\mathrm{cm}^{-1[14]}$ referentes à resposta de hidrogênio ligado, vibrações de esticamento do grupo $\mathrm{C}-\mathrm{H}$ na região $2850-3000 \mathrm{~cm}^{-1[14]}$ e bandas C-O em $1093 \mathrm{~cm}^{-1}$ e $1143 \mathrm{~cm}^{-1}$. A resposta do $\mathrm{TiO}_{2}$ é caracterizada por uma banda larga na faixa de $800-450 \mathrm{~cm}^{-1}$ relativa as vibrações de estiramento do Ti-O, como mostra a curva (b) da Figura 6.

Outro aspecto relevante a ser considerado é a interação das fibras com a luz (regiões do ultravioleta e visível). O espectro de absorção no UV-Vis para amostras na presença/ausência de $\mathrm{TiO}_{2}$ é mostrado na Figura 7.

Como podemos perceber, a presença de nanopartículas de dióxido de titânio no nanocompósito promove elevação no nível de absorção na região do UVA e UVB, em uma indicação de que as fibras de $\mathrm{PVA} / \mathrm{TiO}_{2}$ atuam como potencial candidatos para aplicações em proteção solar (atuando como curativo inteligente) contra os efeitos nocivos da radiação ultravioleta.

Adicionalmente à elevada absorção de luz na região do ultravioleta, outra importante propriedade observada para os compósitos $\mathrm{PVA} / \mathrm{TiO}_{2}$ é a ação fotocatalítica junto ao corante orgânico rodamina $\mathrm{B}$.

Na Figura 8, em uma mesma curva são esboçados os valores de absorbância do pico característico da rodamina B (medida em $547 \mathrm{~nm}$ ) como função do tempo de incidência de luz. A redução dessa grandeza funciona como importante parâmetro na medida da fotodegradação do corante orgânico, exposto a uma radiação luminosa e na presença do fotocatalisador (compósito polimérico).

Como podemos perceber, o aumento na quantidade de fibras a uma concentração fixa de $1 \mathrm{mg} \cdot \mathrm{mL}^{-1}$ de nanopartículas de $\mathrm{TiO}_{2}$ aumenta a eficiência de degradação da rodamina $B$ pela ação contínua de incidência de luz sobre o reator, comprovando que as nanopartículas de dióxido de titânio dispersas na matriz polimérica promovem a formação de radicais reativos que induzem a fotodegradação da rodamina $\mathrm{B}$ e consequente fotoembranquecimento, como detectado pelas curvas de absorbância.

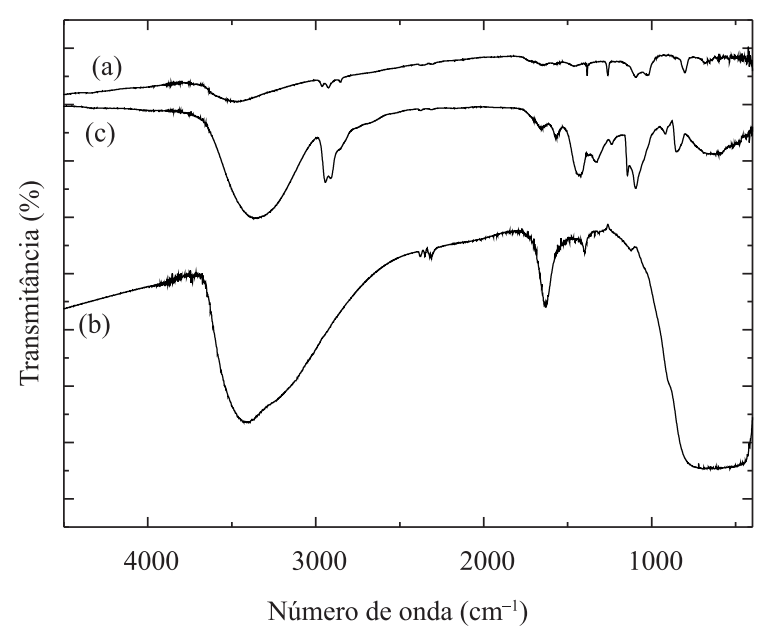

Figura 6. FTIR de fibras de PVA ( $\left.80 \mathrm{mg} \cdot \mathrm{mL}^{-1}\right)$ (curva a), nanopartículas de $\mathrm{TiO}_{2}$ (curva b) e fibras de PVA $\left(80 \mathrm{mg} \cdot \mathrm{mL}^{-1}\right) / \mathrm{TiO}_{2}\left(2,5 \mathrm{mg} \cdot \mathrm{mL}^{-1}\right)$ (curva c).

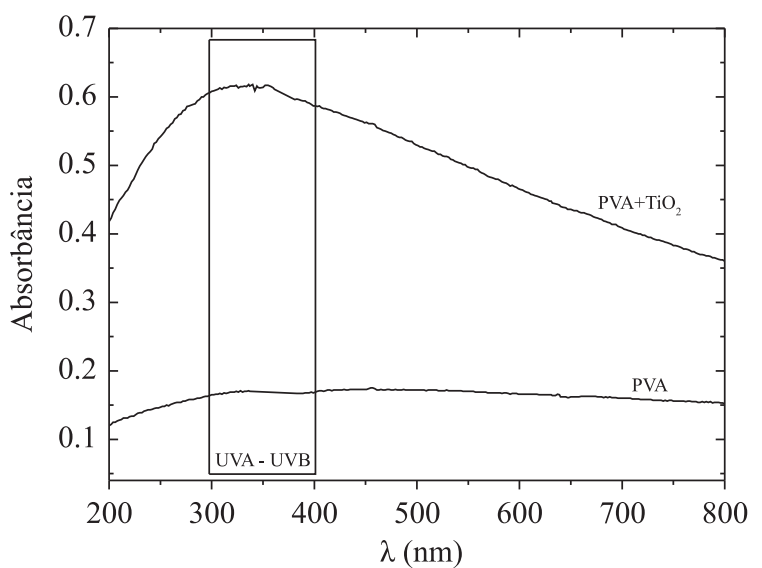

Figura 7. Espectro de absorbância das fibras de PVA $\left(80 \mathrm{mg} \cdot \mathrm{mL}^{-1}\right)$ e PVA $\left(80 \mathrm{mg} \cdot \mathrm{mL}^{-1}\right) / \mathrm{TiO}_{2}\left(2,5 \mathrm{mg} \cdot \mathrm{mL}^{-1}\right)$.

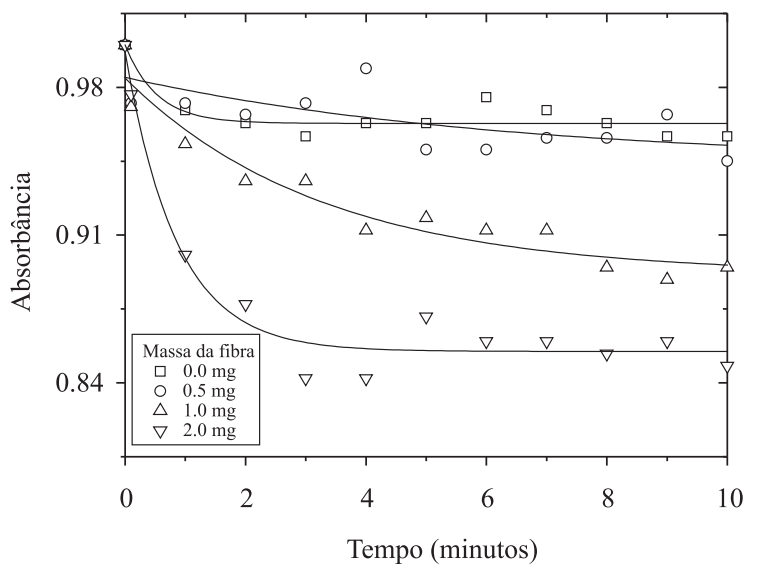

Figura 8. Cinética de fotodegradação da rodamina B como função da quantidade de fibras dispersas em solução aquosa.

\section{Conclusões}

As fibras de $\mathrm{PVA} / \mathrm{TiO}_{2}$ produzidas pela técnica de eletrofiação preservam razoavelmente as propriedades térmicas do suporte (PVA) e introduzem as vantagens do $\mathrm{TiO}_{2}$ na forte absorção de radiação nas regiões UVA e UVB e geração de radicais aplicáveis em processos de fotodegradação de corantes orgânicos. Com o uso de espectroscopia de impedância é possível estabelecer a concentração 
ótima de semicondutor que promove a dispersão mais adequada das partículas na matriz polimérica, o que induz elevada absorção de luz na região do UV e potencial aplicação como protótipo de fotocatalisador. Os resultados obtidos abrem a possibilidade de aplicação da técnica de baixo custo tanto na produção de curativos inteligentes quanto na eliminação de contaminantes pelo uso de processos oxidativos avançados.

\section{Agradecimentos}

Os autores agradecem o apoio financeiro do CNPq, CAPES, FINEP, FACEPE e FAPESB.

\section{Referências Bibliográficas}

1. Khorami, H. A.; Keyanpour-Rad, M. \& Vaezi, M. R. - Appl. Surf. Sci., 257, p.7988 (2011). http://dx.doi.org/10.1016/j. apsusc.2011.04.052

2. Frey, M. W.; Cho, D. W.; Matlock-Colangelo, L.; Xiang, C. H.; Asiello, P. J. \& Baeumner, A. J. - Polymer, 52, p.3413 (2011).

3. Chiellini, E.; Puppi, D.; Piras, A. M.; Detta, N.; Ylikauppila, H.; Nikkola, L.; Ashammakhi, N. \& Chiellini, F. - J. Bioact. Compos. Polym., 26, p.20 (2011).

4. Xu, L.; Yang, C.; Wu, X. M.; Zhao,Y. H. \& Wei, S. C. - J. Appl. Polym. Sci., 121, p.3047 (2011). http://dx.doi.org/10.1002/app.33934

5. Varshosaz, J.; Jannesari, M.; Morshed, M. \& Zamani, M. - Int. J. Nanomed., 6 (2011).

6. West, J. L.; Stephens-Altus, J. S.; Sundelacruz, P. \& Rowland, M. L. - J. Biomed. Mater. Res., Part A, 98A, p.167 (2011).

7. Nirmala, R.; Lee, J.-H.; Navamathavan, R.; Yang, J. H. \& Kim, H. Y. - Mat. Lett., 65, p.2772 (2011). http://dx.doi.org/10.1016/j. matlet.2011.05.100

8. Zhang, Y. Z.; Liao, H. L.; Qi, R. L.; Shen, M. W.; Cao, X. Y.; Guo, R. \& Shi, X. Y. - Colloids Surf., B, 84, p.528 (2011). PMid:21353768.

9. Yeum, J. H.; Yang, J. H.; Yoon, N. S.; Park, J. H.; Kim, I. K.; Cheong, I. W.; Deng, Y. L. \& Oh, W. - J. Appl. Polym. Sci., 120, p.2337 (2011). http://dx.doi.org/10.1002/app.33435

10. Zhou, J. P.; Jia, B. Q. \& Zhang, L. N. - Carbohydr. Res., 346, p.1337 (2011). PMid:21600569.

11. Liu, H. Q.; Tang, C. Y.; Wu, M. Y. \& Wu, Y. Q. - Compos. Part A-Appl. Sci. Manuf., 42, p.1100 (2011).

12. Asran, A. S.; Razghandi, K.; Aggarwal, N.; Michler, G. H. \& Groth, T. - Biomacromolecules, 11, p.3413 (2010). PMid:21090703. http:// dx.doi.org/10.1021/bm100912v

13. Wei, Q .F.; Feng, Q. A.; Xia, X.; Wei, A. F.; Wang, X. Q.; Huo, D. Y. \& Wei, A. J. - J. Appl. Polym. Sci., 120, p.3291 (2011). http://dx.doi. org/10.1002/app.33493
14. Shim, S. E.; Lee, J.; Hong, J.; Park, D. W. - Optical Mat., 32, p.530 (2010).

15. Aminabhavi, T. M.; Sairam, M.; Patil, M. B.; Veerapur, R. S. \& Patil, S.A. - J. Membr. Sci., 281, p.95 (2006). http://dx.doi.org/10.1016/j. memsci.2006.03.022

16. Liu, H.; Cheng, S. A.; Zhang, J. Q.; Cao, C. N. \& Zhang, S. K. - Chemosphere, 38, p.283 (1999). http://dx.doi.org/10.1016/S00456535(98)00196-9

17. Benabbou, A. K.; Derriche, Z.; Felix, C.; Lejeune, P. \& Guillard, C. - Appl. Catal., B, 76, p.257 (2007). http://dx.doi.org/10.1016/j. apcatb.2007.05.026

18. Antoniou, C.; Kosdamaki, M. G.; Stratigos, A. J. \& Katsambas, A. D. - J. Eur. Acad. Dermat. Vener., 22, p.1110 (2008). http://dx.doi. org/10.1111/j.1468-3083.2007.02580.x

19. Nasu, A. \& Otsubo, Y. - J. Colloid Interface Sci., 310, p.617 (2007). PMid:17376475. http://dx.doi.org/10.1016/j.jcis.2007.02.012

20. Dunford, R.; Salinaro, A.; Cai, L.; Serpone, N.; Horikoshi, S.; Hidaka, H. \& Knowland, J. - FEBS Letters, 418, p.87 (1997). http://dx.doi. org/10.1016/S0014-5793(97)01356-2

21. Zholobak, N. M.; Ivanov, V. K.; Shcherbakov, A. B.; Shaporev, A. S.; Polezhaeva, O. S.; Baranchikov, A. Y.; Spikav, N. Y. \& Tretyakov, Y. D. - J. Photochem. Photobiol., B, 102, p.32 (2011). PMid:20926307. http://dx.doi.org/10.1016/j.jphotobiol.2010.09.002

22. Popov, A. P.; Priezzhev, A. V.; Ladermann, J.; Myllyla, R. - J. Appl. Phys., 105, p.102035 (2009).

23. Ma, Z.; Ji, H.; Tan, D.; Teng, Y.; Dong, G.; Zhou, J.; Qiu, J.; Zhang, M. - Coll. Surf. A: Physicochem. Eng. Asp., 387, p.57 (2011). http:// dx.doi.org/10.1016/j.colsurfa.2011.07.025

24. Shalumon, K. T.; Anulekha, K. H.; Nair, S. V.; Nair, S. V.; Chennazhi, K. P.; Jayakumar, R. - Int. J. Biolog. Macrom., 49, p.247 (2011). PMid:21635916. http://dx.doi.org/10.1016/j.ijbiomac.2011.04.005

25. Kim, Y. S.; Linh, L. T.; Park, E. S.; Chin, S.; Bae, G.-N.; Jurng, J. - Powder Technol., 215-216, p. 195 (1012).

26. Wei, S. Y.; Ding, W.; Zhu, J. H.; Chen, X. L.; Rutman, D.; Guo, Z. H. - Macromol. Mater. Eng., 295, p.958 (2010).

27. Oliveira, H. P.; Santos, C. G.; Melo, C. P.; Santos, M. V. B. - Synth. Met., 135, p.447 (2003).

28. Oliveira, H. P.; Andrade, C. A. S.; Melo, C. P. - Synth. Met., 155, p. 631 (2005). 